\title{
Agenda ecológica: o dualismo esquerda-direita e a clivagem
}

\section{ambiental na esquerda ${ }^{1}$}

\author{
Agenda ecológica: el dualismo izquierda-derecha y el clivaje ambiental en \\ la izquierda
}

Ecological agenda: left-right dualism and the environmental cleavage in

the left

Marcos Todt ${ }^{2}$

\begin{abstract}
Resumo
O advento das questões pós-materialistas foi um dos principais fatores que colocou em debate a validade dos conceitos esquerda e direita como sistema classificatório de posicionamentos políticos. Desse modo, a dicotomia esquerda-direita segue fazendo sentido no contexto das discussões ambientais contemporâneas? Através de pesquisa bibliográfica, verifica-se que sim, pois as visões de mundo têm forte impacto sobre a crença ou o ceticismo em relação ao consenso científico acerca da crise ambiental, e tanto cidadãos como partidos de esquerda têm maior abertura à causa ecológica. Não obstante, nota-se a existência de visões substancialmente diferentes em relação à temática ambiental no interior do espectro político da esquerda. Essa diferença, que denominamos clivagem ambiental na esquerda, se dá a partir de entendimentos antagônicos sobre o conceito de desenvolvimento: parte da esquerda defende um desenvolvimento alternativo, apostando no crescimento econômico e no papel do Estado como indutor da economia, e parte entende que o desenvolvimento é um dos dispositivos-chave do capitalismo e incompatível com o combate à pobreza e com a preservação ambiental.
\end{abstract}

Palavras-chave: Alternativas ao desenvolvimento; Ecologia; Esquerda; Esquerda-direita; Pós-materialismo.

\section{Resumen}

El advenimiento de las cuestiones post-materialistas ha sido uno de los factores principales que han puesto en discusión la validez de los conceptos izquierda y derecha como un sistema de clasificación de posiciones políticas. De esta manera, ¿la dicotomía izquierda-derecha sigue teniendo sentido en el contexto de las discusiones ambientales contemporáneas? A través de la investigación bibliográfica, se verifica que sí, porque las visiones del mundo tienen un fuerte impacto en las creencias o el escepticismo con respecto al consenso científico sobre la crisis ambiental, y tanto los ciudadanos como los partidos de izquierda tienen una mayor apertura a la causa ecológica. Sin embargo, se puede observar la existencia de puntos de vista muy diferentes en relación con el tema ambiental dentro del espectro político de la izquierda. Esta diferencia, que llamamos clivaje ambiental en la izquierda, se basa en entendimientos antagónicos sobre el concepto de desarrollo: parte de la izquierda aboga por un desarrollo alternativo, apostando por el crecimiento económico y el papel del Estado como inductor de la economía, y parte entiende que el desarrollo es uno de los dispositivos clave del capitalismo e incompatible con el combate a la pobreza y con la preservación del medio ambiente.

Palabras claves: Izquierda; Izquierda-derecha; Alternativas al desarrollo; Ecología; Postmaterialismo.

\section{Abstract}

The advent of post-materialist questions was one of the main factors that evidenced the debate on the validity of the concepts of left and right as a classification system of political positions. In this way, does the left-right

\footnotetext{
${ }^{1}$ O presente trabalho foi realizado como o apoio da Coordenação de Aperfeiçoamento de Pessoal Nível Superior - Brasil (CAPES) - Código de Financiamento 001.

${ }^{2}$ Doutorando em Ciências Sociais pela PUCRS; membro do Centro Brasileiro de Pesquisas em Democracia (CBPD); Porto Alegre, Rio Grande do Sul, Brasil; E-mail: marcos.todt@edu.pucrs.br.
} 
dichotomy continue to make sense in the context of contemporary environmental discussions? Through bibliographic research, this study verified that yes, since world views have a strong impact on belief or skepticism regarding the scientific consensus on the environmental crisis, and both citizens and leftist parties have greater openness to the ecological cause. Nonetheless, results also indicated the existence of visions that are substantially different in relation to the environmental theme within the political spectrum of the left. This difference, which is this study is called environmental cleavage on the left, is based on antagonistic understandings about the concept of development: part of the left advocates an alternative development, betting on economic growth and on the role of the State as an promoter of economy, and other part understands that development is one of the key devices of capitalism and, therefore, is incompatible with the fight against poverty and the environmental preservation.

Keywords: Alternatives to development; Ecology; Left; Left-right cleavage; Post-materialism.

\section{Introdução}

O advento das questões pós-materialistas é um elemento central, junto com a queda do muro de Berlim e o colapso da União Soviética, para o surgimento de sensação de indiferenciação dos partidos políticos que colocou em debate o sentido dos conceitos esquerda e direita, após terem ocupado, desde a Revolução Francesa, um papel central como sistema classificatório de posicionamentos políticos (MADEIRA; TAROUCO, 2011).

Para exemplificar a intensidade do debate sobre a validade da dicotomia esquerdadireita, no ano de 1994 Anthony Giddens e Norberto Bobbio publicaram obras relevantes sobre o tema com pontos de vista antagônicos. Giddens (1996) afirmou taxativamente que as perspectivas políticas representadas pelos termos direita e esquerda estão esgotadas, em consequência da globalização e do surgimento de uma sociedade pós-tradicional, que causa o que o autor denomina modernização reflexiva e traz mudanças em nosso relacionamento com o desenvolvimento social moderno. Por seu turno, Bobbio (1995) afirmou a validade do dualismo e defendeu o modo como se compreende a ideia da igualdade como critério para distinguir esquerda e direita. Tratamos, na primeira seção deste artigo, sobre a pertinência ou não da dualidade esquerda-direita ao se tratar especificamente de assuntos ligados à ecologia.

Entrementes, para além da clivagem esquerda-direita, há um debate atual na esquerda entre a esquerda que aposta no desenvolvimento e a esquerda não desenvolvimentista. A primeira acredita no desenvolvimento através do crescimento econômico do papel do Estado como indutor da economia. A segunda afirma que é necessário que a esquerda se liberte do que chamam mito do desenvolvimento e construa alternativas ao largo dessa concepção. Esse debate constitui o que denominamos clivagem ambiental na esquerda, que ocorre ao se colocar no centro da discussão a ideia de desenvolvimento e a consequente visão de mundo atrelada ao binômio desenvolvimento/subdesenvolvimento. Na segunda seção, trataremos sobre a clivagem ambiental na esquerda, priorizando, para demonstrar essa dualidade, as 
críticas da esquerda não desenvolvimentista à ideia de desenvolvimento. À terceira seção, tecemos as considerações finais.

Para tratar de ambos os temas, ou seja, a validade ou não da dicotomia esquerdadireita no que diz respeito à temática ecológica e a clivagem ambiental na esquerda, recorremos à pesquisa bibliográfica.

\section{Sobre a pertinência do dualismo esquerda-direita na temática ambiental}

Para Inglehart (2012), o processo de mudança na sociedade, da primazia dos valores aquisitivos para os valores pós-materialistas, não elimina a clivagem esquerda-direita, pois segue existindo o embate entre as forças da mudança contra as forças do status-quo. No entanto, como as mudanças se referem a estilo de vida e não a valores aquisitivos, as pessoas com valores pós-materialistas formariam uma nova esquerda, em contraposição à velha esquerda, cuja ênfase são os temas econômicos.

Para Savage (1985), a clivagem esquerda-direita segue viva, não devendo ser substituída pelo conflito pós-materialista versus materialista num futuro próximo: o conjunto de questões que caracteriza o debate entre materialistas e pós-materialistas, como a liberdade de expressão, combate ao crime, melhora da qualidade do trabalho e proteção ao meio ambiente versus crescimento econômico, pode ser vista claramente através da relação esquerda-direita. Em vez de substituir a clivagem esquerda-direita, os valores pósmaterialistas a atualizam, pois as novas questões políticas e sociais colocadas por esses novos valores estarão sujeitas ao tradicional debate ideológico e à criação de políticas públicas. $\mathrm{O}$ autor ilustra com um exemplo concreto:

\footnotetext{
Uma variedade de indicadores econômicos sugere que a Califórnia é a região político-geográfica mais pós-industrial do mundo; Mas os esforços para resolver problemas públicos criam políticas significativamente diferentes no sul da Califórnia relativamente conservador do que no norte da Califórnia. Em outras palavras, embora os californianos sejam pós-materialistas por causa da alta prioridade que colocam, por exemplo, na proteção do meio ambiente, como essa proteção é traduzida em política e implementada depende de atitudes ideológicas sobre o papel do governo na sociedade (SAVAGE, 1985, p. 449-450, tradução nossa).
}

Em pesquisa realizada no Reino Unido, Whitmarsh (2011) verificou que o ceticismo sobre a mudança climática é mais fortemente determinado pelos valores ambientais e políticos dos indivíduos do que pela educação ou pelo conhecimento. Ou seja, a variável mais forte relacionada ao ceticismo não é a falta de informação, pois os "céticos do clima" baseiam-se 
na ideologia e não em evidências, e valores pró-ambientais e visões políticas mais à esquerda predispõem os indivíduos a acreditar na realidade e severidade das mudanças climáticas.

Baseada na descoberta de que orientação política e ideologia estão entre as influências mais significativas nas atitudes e respostas à mudança climática, e que há forte relação entre visões políticas de direita e menor preocupação e maior ceticismo sobre a mudança climática, Whitmarsh e Corner (2017) realizaram trabalho no Reino Unido em que se desenvolveu e testou uma série de narrativas para envolver melhor as pessoas com visões à direita com a causa ambiental. Os resultados indicaram que a narrativa que associou a ideia de economizar energia ao princípio conservador de evitar o desperdício, e a narrativa baseada no apoio patriótico das tecnologias nacionais de baixo carbono reduziram o ceticismo, enquanto o argumento tipicamente mais à esquerda da justiça climática não conseguiu o mesmo resultado (WHITMARSH; CORNER, 2017). Em investigação também realizada na Grã-Bretanha, Poortinga et al. (2011) confirmou os resultados de Whitmarsh (2011), inferindo que o ceticismo climático é particularmente comum entre indivíduos que são politicamente conservadores e possuem valores tradicionais.

Estudos realizados nos Estados Unidos chegaram às mesmas conclusões. Kahan (2015) liderou pesquisa que verificou que apenas $22 \%$ das pessoas identificadas com a direita acreditam que a atividade humana é a principal fonte de aquecimento global, contra cerca de 75\% das pessoas identificadas com a esquerda. Kahan, Jenkins-Smith e Braman (2011) e Kahan (2015) verificaram que os indivíduos tendem a assimilar a informação ajustando-a a modelos ou esquemas narrativos pré-existentes que dão significado à informação. Quando são mostradas informações de risco que associam a uma conclusão que ameaça seus valores culturais (por exemplo: as temperaturas globais estão aumentando, portanto o comércio deve ser restringido), os indivíduos tendem a reagir com desdém a essa informação; no entanto, quando as informações são consistentes com uma conclusão que afirma seus valores culturais, a probabilidade de que considerem a informação de mente aberta é maior (KAHAN; JENKINS-SMITH; BRAMAN, 2011).

Ainda nos Estados Unidos, Smith e Leiserowitz (2012) demonstraram que os democratas são mais propensos a perceber o aquecimento global como um risco do que os republicanos, enquanto Dunlap, Xiao e McCright (2001) verificaram que os eleitores republicanos são significativamente menos favoráveis a fortes políticas de proteção ambiental do que os eleitores democratas.

O alemão Neumayer (2004), pesquisador da London School of Economics and Political Science, demonstrou, através de análise de dados baseada em considerável amostra 
transnacional, que tanto os partidos de esquerda têm maior disposição para abraçar questões pró-ambientais em manifestos eleitorais como indivíduos de esquerda são mais propensos a crenças, comportamentos e atitudes pró-ambientais. Analisando a política brasileira, Gatto e Power (2016) verificaram relação entre a clivagem materialista/pós-materialista e a clivagem esquerda-direita através de análise de dados do Congresso Nacional coletados pela Pesquisa Legislativa Brasileira em 2013. Entre os principais partidos políticos do Congresso, os de esquerda tiveram pontuações mais altas em uma bateria de perguntas abrangendo doze itens do pós-materialismo, enquanto o índice mais baixo foi do Democratas (DEM).

Conforme Thérien (2012), há claras diferenças entre a esquerda e a direita em relação ao tema ambiental. Para o autor, não raro a direita julga que as análises dos ambientalistas são alarmistas, têm tendência para acreditar que a tecnologia resolverá os problemas ambientais. Tanto em nível global como nacional, os políticos de direita defendem que a proteção do meio ambiente não deve comprometer o objetivo do crescimento econômico, preferem medidas voluntárias, em vez de coercitivas, para proteger o meio ambiente, e demonstram-se pouco entusiasmados com a criação de mecanismos internacionais como uma Organização Mundial do meio ambiente ou de um Conselho de segurança ambiental. Em contrapartida, a esquerda em geral considera que a proteção do meio ambiente representa uma urgência absoluta para o futuro da humanidade e é mais crítica em relação ao modelo de desenvolvimento centrado no crescimento, denunciando como inviável o estilo de vida das populações do Norte. Considera que o laissez-faire conduziria a uma destruição do planeta e, por conseguinte, defende um reforço das instituições e das normas nacionais e internacionais, preferindo medidas preventivas e sanções em vez de medidas voluntárias e defendendo a aplicação de taxas sobre o comércio internacional, por exemplo, na utilização de energias não renováveis.

A literatura, portanto, demonstra que há relação entre identificação ideológica e posicionamento perante as questões ambientais. As visões de mundo têm impacto maior do que o nível educacional ou de acesso à informação sobre a crença ou o ceticismo em relação ao consenso científico sobre a crise ambiental. Além disso, tanto cidadãos como partidos de esquerda têm maior abertura à causa ecológica. A tradicional clivagem esquerda-direita segue fazendo sentido no contexto das discussões ambientais contemporâneas.

Trataremos a seguir das diferenças existentes dentro do campo da esquerda: existe atualmente um profundo debate sobre a compreensão que a esquerda deve ter sobre a ideia do desenvolvimento, que afeta diretamente as questões relacionadas à ecologia. 
RELACult - Revista Latino-Americana de Estudos em Cultura e Sociedade

\title{
3. A clivagem ambiental na esquerda: o desenvolvimento no centro do debate
}

Ao analisar os governos progressistas eleitos na América Latina - incluindo o Brasil a partir de 1999, Gudynas (2011, 2012), Lang (2011, 2016, 2017) e Acosta (2016) avaliam que os citados governos priorizaram o crescimento econômico, minimizaram os obstáculos ambientais, mantiveram os procedimentos convencionais de apropriação e comercialização de recursos naturais e não colocaram em discussão o pressuposto do desenvolvimento como crescimento econômico. Para os autores, essa é uma grave limitação de uma esquerda que, conforme Lang (2011), não compreendeu que o conceito de desenvolvimento, que faz crer que bem-estar é sinônimo de consumo, é elemento central para a reprodução e expansão do capitalismo e para o agravamento da crise ecológica.

O imaginário do desenvolvimento tem como divisor de águas o discurso do então presidente dos Estados Unidos, Harry Truman, em 20 de janeiro de 1949:

\begin{abstract}
Devemos embarcar em um novo programa para disponibilizar os benefícios de nossos avanços científicos e nosso progresso industrial pra a melhoria e o crescimento das regiões subdesenvolvidas. (...) Com a cooperação das empresas, do capital privado, da agricultura e da mão de obra deste país, este programa pode aumentar bastante a atividade industrial em outras nações e elevar substancialmente os padrões de vida. (...) O velho imperialismo - exploração para benefício estrangeiro - não tem lugar em nossos planos. O que vislumbramos é um programa de desenvolvimento baseado nos conceitos de uma relação limpa e democrática. (...) Maior produção é a chave para a prosperidade e a paz. E a chave para uma produção maior é uma aplicação mais ampla e vigorosa do conhecimento científico e técnico moderno (TRUMAN, 1949, tradução nossa).
\end{abstract}

De acordo com Lang (2017), a ideia do desenvolvimento nasce após a segunda guerra mundial porque a prática de civilizar e explorar aos colonizados para benefício próprio já não era viável, após as diversas lutas por independência e o combate ao nazismo. Assim, a exploração direta foi substituída pelo mandato de desenvolver os subdesenvolvidos. O desenvolvimento se torna meta das políticas públicas e se destinam orçamentos e uma série de instituições para impulsioná-lo, como, por exemplo, a Organização das Nações Unidas (ONU), que nasceu com o propósito de evitar guerras, mas logo se transformou em uma das principais promotoras do desenvolvimento, o Fundo Monetário Internacional (FMI) e o Banco Mundial (BM).

No mesmo sentido, Moreno, Speich e Fuhr (2016) argumentam que quando o imperialismo ainda era incontestado, antes de 1945, ninguém na Europa pensava nas colônias como regiões economicamente atrasadas. As colônias eram consideradas racialmente inferiores e culturalmente atrasadas, porém ricas em recursos econômicos. No entanto, com a 
mentalidade estatística dos economistas majoritários, as periferias de repente transformaramse em países economicamente subdesenvolvidos:

\begin{abstract}
Os economistas definiram os mundos sociais não-europeus como sendo diferentes do modelo europeu em termos negativos, no sentido de ainda não terem alcançado a forma econômica ocidental. A estatística tornou visível o não-ocidental como uma entidade deficiente e não como uma multiplicidade criativa. Assim, embora oferecesse ferramentas poderosas para a descolonização, a economia do desenvolvimento também prolongou estruturas coloniais de dominação no mundo pós-colonial. Uma visão aguçada dos novos estados "subdesenvolvidos" emergiu, mas a presunção da supremacia do Ocidente permaneceu incontestada (MORENO; SPEICH; FUHR, 2016, p. 55-56).
\end{abstract}

Na esteira da concepção e do objetivo do desenvolvimento, é gerado um novo marco analítico para visualizar "realidades" econômicas, com um discurso global baseado em um conjunto de abstrações macroeconômicas - o Produto Interno Bruto (PIB), a renda per capita e o crescimento econômico - que produz uma nova visão de mundo com foco no binômio desenvolvimento-subdesenvolvimento. Desse modo, no momento em que o modo de vida capitalista/moderno/ocidental foi estabelecido através do exercício de contabilidade comparativa global que significou a construção do PIB, automaticamente outros modos de vida foram etiquetados como subdesenvolvidos, deficientes e pobres (LANG, 2017).

De fato, não é menos importante observar que as noções de desenvolvimento e subdesenvolvimento foram baseadas em aspectos quantitativos e econômicos. Como frisou Unceta (2014), esses conceitos poderiam se basear em diversos aspectos do bem-estar humano, como educação, saúde, eficiência ambiental, mas desde o princípio estiveram vinculados a análises comparativas das taxas de crescimento.

Fleury (2013) pontua que o conceito de desenvolvimento traz consigo a ideia de que os lugares não desenvolvidos são lugares atrasados, anacrônicos, que devem se adequar ao tempo presente. Essa ideia de linearidade histórica, embutida no paradigma desenvolvimentista, faz com que seja necessário lutar pelo próprio direito de existir no tempo presente de modo diferente ao considerado adequado, ou moderno (FLEURY, 2013). Essa visão de mundo forçou adaptações que não respeitaram a diversidade cultural, como já apontavam na década de 1950 especialistas reunidos a pedido da ONU:

Há um sentido em que o progresso econômico acelerado é impossível sem ajustes dolorosos. As filosofias ancestrais devem ser erradicadas; as velhas instituições sociais têm que se desintegrar; os laços de casta, credo e raça devem ser quebrados; e grandes massas de pessoas incapazes de acompanhar o progresso deverão ver suas expectativas de uma vida confortável frustradas (NAÇÕES UNIDAS, 1951 apud ESCOBAR, 2007, p. 20, tradução nossa). 
Um exemplo disso é a análise de N'Dione et al. (1997 apud LANG, 2017), de que na África a cultura do desenvolvimento promove o empobrecimento e a solidão através de conceitos e valores exógenos como uma concepção economicista do tempo, a competição entre as pessoas em vez da cooperação, a mercantilização das pessoas e das coisas. Segundo Castoriadis (2006), há uma obsessão pelo aumento do consumo e da produção que é praticamente ausente nas outras fases da história. $\mathrm{O}$ imaginário capitalista faz internalizar a lógica de que a meta da vida humana seria exatamente a expansão ilimitada da produção e do consumo, para o atingimento de um suposto bem-estar material. Esse imaginário exerce sobre os povos uma forte fascinação:

\begin{abstract}
Se tem visto a todos os povos da terra, ou a quase todos, passarem a imitar - e aos pobres, a imitar na miséria - o modo de vida e a organização capitalista. Para o capitalismo houve então a possibilidade de exercer uma violência direta, baseada no desenvolvimento técnico e econômico, o que relativamente representa pouco mistério; mas também esta outra violência exercida pelo fascínio, pela representação pura e simples desta sociedade capitalista avançada que desempenha o papel de modelo universal. Ambas as coisas combinadas conduzem a esta vitória por ora universal do capitalismo (CASTORIADIS, 2006, p. 98-99, tradução nossa).
\end{abstract}

Esse fascínio pelo desenvolvimento acaba por justificar uma série de ações necessárias para se atingir o desejado desenvolvimento. Para Furtado (1974) a ideia (irrealizável) de que os povos pobres terão algum dia as formas de vida existentes nos países desenvolvidos tem sido de grande utilidade para justificar formas de dependência, a destruição de formas de cultura consideradas arcaicas e do meio ambiente, tornando possível desviar o foco das necessidades fundamentais da coletividade em direção a objetivos abstratos como os investimentos, as exportações e o crescimento.

Mesmo durante a Guerra Fria, essa concepção foi hegemônica em nível mundial. Conforme Lang (2017), se o paradigma do desenvolvimento surgiu a partir dos Estados Unidos e se expandiu rapidamente pelas zonas de influência capitalista, abarcou também a outra potência da Guerra Fria, a União Soviética. Nas palavras de Lander (2008, p. 11),

O marxismo realmente existente, ao assumir no fundamental as concepções e práticas em relação à verdade, ciência e tecnologia que têm sido dominantes no mundo ocidental, tem encontrado insuperáveis limitações em sua capacidade de crítica à sociedade capitalista, não somente como forma de organização da propriedade ou de exercício do poder, mas como modelo civilizatório. Apesar de sua profundidade e radicalidade, a crítica marxista ao mundo do capital - por assumir no essencial a noção de progresso (...) levou ao marxismo realmente existente à imposibilidade de pensar outro mundo alternativo à sociedade tecnológica altamente centralizada y unidimensionalmente produtivista, desenvolvida historicamente pelo regime do capital (tradução nossa). 
Löwy (2014) tece considerações semelhantes. O sociólogo franco-brasileiro afirma que durante os primeiros anos da Revolução Russa o movimento ecologista pôde se desenvolver e foram adotadas algumas medidas, mesmo que limitadas, de proteção ambiental. No entanto, a partir de Stálin se constitui a ideologia do progresso e ocorre a aplicação, por meios autoritários, de métodos produtivistas na agricultura e na indústria, com a marginalização ou eliminação dos ecologistas. Para Latouche (2009), se não integrar as exigências ecológicas e superar a ideia de desenvolvimento, o projeto da esquerda marxista apenas criticará o sistema capitalista sem, no entanto, conseguir questionar seu princípio.

Ao criticar a adesão da esquerda ao desenvolvimentismo, Gudynas (2011, 2012), Lang (2011, 2016, 2017) e Acosta (2016) diferenciam “desenvolvimentos alternativos" de "alternativas ao desenvolvimento"3. O primeiro caso constitui-se de opções distintas de desenvolvimento que aceitam as premissas da busca pelo crescimento permanente e da apropriação da natureza. Já as "alternativas ao desenvolvimento" são defendidas pela esquerda não desenvolvimentista que afirma a necessidade de superação do mito do desenvolvimento.

A esquerda não desenvolvimentista defende a tese de que a esquerda que não questiona o mito do progresso e do desenvolvimento, em que pese sua intenção antissistêmica, acaba reforçando a base de sustentação do sistema capitalista e destruindo modos de vida alternativos. Nas palavras de Lang (2017, p. 128):

\begin{abstract}
Seu paradigma redistributivo estreito, centrado em lógicas quantitativas, os meios de produção e os recursos, girou ao redor de valores produtivistas e reforçou imaginários de bem-estar relacionados à posse de dinheiro, bens e serviços. Invisibilizaram outras formas de conceber a materialidade, a natureza, e outros modos de vida que não estavam organizados ao redor do crescimento material ilimitado, mas da sustentabilidade da vida. Invisibilizaram ainda as dimensões sociais, relacionais e espirituais inerentes a qualquer forma de bem viver, e grande parte das formas de trabalho existentes nas sociedades humanas.
\end{abstract}

Desse modo, a esquerda não desenvolvimentista entende que a esquerda não deve se limitar a debater desenvolvimentos alternativos, mas buscar alternativas civilizatórias à margem da civilização capitalista/moderna/ocidental e, como pontua Lang (2017), que tenham percepções diferentes sobre o que é a felicidade, a qualidade de vida e o sentido da convivência humana.

\footnotetext{
${ }^{3}$ Conforme Gudynas (2012), a distinção entre desenvolvimentos alternativos e alternativas ao desenvolvimento foi baseada nos aportes constantes na obra $A$ invenção do terceiro mundo: construção e desconstrução do desenvolvimento (tradução nossa), do antropólogo colombiano Arturo Escobar (ESCOBAR, 2007).
} 


\section{Conclusões}

Concluímos nossa reflexão reconhecendo que tão importante quanto pensar sobre a validade da dicotomia esquerda-direita em relação aos chamados temas pós-materialistas, dentre os quais se inclui as questões ambientais, é compreendermos sobre as diferenças existentes dentro de cada campo. No caso específico que tratamos neste artigo, o debate que se faz hoje no seio da esquerda é de grande riqueza, com consequências diretas para os programas de governo e as propostas que tendem a ser apresentados pelos partidos e movimentos sociais/ambientais em um futuro próximo.

Há duas visões - antagônicas - no seio da esquerda que constitui o que chamamos clivagem ambiental na esquerda: uma, considera o desenvolvimento como instrumento para se alcançar profunda transformação social; outra, considera que o desenvolvimento como um dos dispositivos-chave para afiançar e expandir o capitalismo, que amarra o bem-estar unicamente à capacidade de consumo das pessoas

As diferentes compreensões sobre o significado do desenvolvimento repercutem tanto em posicionamento sobre temas tradicionais como o combate à pobreza e à desigualdade, como também sobre como responder à crise ambiental que coloca em risco o futuro da humanidade.

\section{Referências}

ACOSTA, A. O bem viver: uma oportunidade para imaginar outros mundos. São Paulo: Autonomia Literária/Elefante, 2016. 258 p.

BOBBIO, N. Direita e esquerda: razões e significados de uma distinção política. São Paulo: Editora da Universidade Estadual Paulista, 1995.

CASTORIADIS, C. Una sociedad a la deriva: entrevistas e debates, 1974-1997. Buenos Aires: Katz, 2006.

DUNLAP, R. E.; XIAO, C.; McCRIGHT, A. M. Politics and environment in America: Partisan and ideological cleavages in public support for environmentalism. Environmental Politics, [S.1.], v. 10, p. 23-48, 2001. Disponível em:

https://www.academia.edu/35184386/Politics_and_Environment_in_America_Partisan_and_I deological_Cleavages_in_Public_Support_for_Environmentalism. Acesso em: 12 fev. 2019.

ESCOBAR, A. La invención del tercer mundo: construcción y deconstrucción del desarrollo. Caracas: Fundación Editorial El Perro y la Rana, 2007. 
FLEURY, L. Conflito ambiental e cosmopolíticas na Amazônia brasileira: a construção da Usina Hidrelétrica de Belo Monte em perspectiva. 2013. 320 f. Tese (Doutorado em Sociologia) - Universidade Federal do Rio Grande do Sul, Porto Alegre, 2013.

FURTADO, C. O mito do desenvolvimento econômico. Rio de Janeiro: Paz e Terra, 1974.

GATTO, M.; POWER, T. Postmaterialism and political elites: the value priorities of Brazilian federal legislators. Journal of Politics in Latin America, [S.1.], v. 8, n. 1, p. 33-68, 2016. Disponível em: https://journals.sub.uni-hamburg.de/giga/jpla/article/view/939/946. Acesso em: 10 dez. 2019.

GIDDENS, A. Para além da esquerda e da direita: o futuro da política radical. São Paulo: Editora da Universidade Estadual Paulista, 1996.

GUDYNAS, E. Buen vivir y críticas al desarrollo: saliendo de la modernidad por la izquierda. In: HIDALGO, F. E.; MÁRQUEZ, A. Contrahegemonía y Buen Vivir. Quito: Universidad Central del Ecuador/Universidad del Zulia, 2012. p. 71-91.

GUDYNAS, E. Debates sobre el desarrollo y sus alternativas en América Latina: una breve guía heterodoxa. In: LANG, M.; MOKRANI, D. (Orgs.). Más allá del desarrollo: grupo de trabajo permanente sobre alternativas al desarrollo. Quito: Fundación Rosa Luxemburgo/Abya-Yala, 2011. p. 21-54.

INGLEHART, R. A revolução silenciosa na Europa: mudança intergeracional nas sociedades pós-industriais. Revista de Sociologia e Política, Curitiba, v. 20, n. 43, p. 159-191, out. 2012. Disponível em: http://www.scielo.br/scielo.php?script=sci_arttext\&pid=S0104$44782012000300008 \& \operatorname{lng}=e n \& n r m=i s o$. Acesso em: 10 fev. 2019.

KAHAN, M. Climate-science communication and the measurement problem. Advances in Political Psychology, [S.1.], v. 36, p. 1-43, 2015. Disponível em: https://ssrn.com/abstract=2459057. Acesso em: 14 fev. 2019.

KAHAN, M.; JENKINS-SMITH, H.; BRAMAN, D. Cultural Cognition of Scientific Consensus. Journal of Risk Research, [S.1.], v. 14, p. 147-174, 2011. Disponível em: http://media.usm.maine.edu/ lenny/Bullshit/values\%20paper.pdf. Acesso em: 14 fev. 2019.

LANDER, E. Contribución a la crítica del marxismo realmente existente: verdad, ciencia y tecnología. Caracas: El Perro y la Rana, 2008. 327 p.

LANG, M. Alternativas ao desenvolvimento. In: DILGER, G.; LANG, M.; PEREIRA FILHO, J. (Orgs.). Descolonizar o imaginário: debates sobre pós-extrativismo e alternativas ao desenvolvimento. São Paulo: Fundação Rosa Luxemburgo, 2016. p. 24-44.

. Crisis civilizatoria y desafíos para las izquierdas. In: LANG, M.; MOKRANI, D. (Orgs.). Más allá del desarrollo: grupo de trabajo permanente sobre alternativas al desarrollo. Quito: Fundación Rosa Luxemburgo/Abya-Yala, 2011.p. 7-18.

- ¿Erradicar la pobreza o empobrecer las alternativas? Quito: Universidad Andina Simón Bolívar/Abya-Yala, 2017. 159 p. 
LATOUCHE, S. Pequeno tratado do decrescimento sereno. São Paulo: WMF Martins Fontes, 2009. 146 p.

LÖWY, M. O que é ecossocialismo? 2. ed. São Paulo: Cortez, 2014. 128 p.

MADEIRA, R.; TAROUCO, G. Esquerda e Direita no Brasil: uma análise conceitual. Revista Pós Ciências Sociais, São Luís, v. 8, n. 15, p. 171-185, jan./jun. 2011. Disponível em: http://www.periodicoseletronicos.ufma.br/index.php/rpcsoc/article/view/591. Acesso em: 16 fev. 2019.

MORENO, C.; SPEICH, D.; FUHR, L. A métrica do carbono: abstrações globais e epistemicídio ecológico. Rio de Janeiro: Fundação Heinrich Böll, 2016.

NEUMAYER, E. The environment, left-wing political orientation and ecological economics. Ecological Economics, [S.1.], v. 51, p. 167-175, 2004. Disponível em: http://www.lse.ac.uk/websitearchive/GeographyAndEnvironment/neumayer/pdf/Article\%20in\%20Ecological\%20Economi cs\%20(Left-wing\%20orientation).pdf. Acesso em: 12 fev. 2019.

POORTINGA, W. et al. Uncertain climate: an investigation into public scepticism about anthropogenic climate change. Global Environmental Change, [S.1.], v. 21, p. 1015-1024, 2011. Disponível em: http://citeseerx.ist.psu.edu/viewdoc/download?doi=10.1.1.454.2893\&rep=rep1\&type=pdf. Acesso em: 14 fev. 2019.

SAVAGE, J. Postmaterialism of the Left and Right political conflict in postindustrial society. Comparative Political Studies, [S.1.], v. 17, p. 431-451, 1985. Disponível em: https://www.researchgate.net/publication/258130319_Postmaterialism_of_the_Left_and_Righ t_Political_Conflict_in_Postindustrial_Society. Acesso em: 10 fev. 2019.

SMITH, N.; LEISEROWITZ, A. The rise of global warming skepticism: Exploring affective image associations in the united states over time. Risk Analysis, [S.1.], v. 32, p. 1021-1032, 2012. Disponível em: https://onlinelibrary.wiley.com/doi/epdf/10.1111/j.1539-

6924.2012.01801.x. Acesso em: 12 fev. 2019.

THÉRIEN, J. P. A internacionalização da divisão esquerda-direita. In: CORREIA, V (Org.). A dicotomia política esquerda-direita: a problemática da sua validade e atualidade. Lisboa: Fonte da Palavra, 2012.

TRUMAN, H. S. Inaugural address. Truman Library, Washington, 20 jan. 1949. Disponível em: https://www.trumanlibrary.org/whistlestop/50yr_archive/inagural20jan1949.htm. Acesso em: 11 fev. 2019.

UNCETA, K. Desarrollo, postcrecimiento y buen vivir: debates e interrogantes. Quito: AbyaYala, 2014. 
WHITMARSH, L. Scepticism and uncertaintyabout climate change: dimensions, determinants and change over time. Global Environmental Change, [S.1.], v. 21, p. 690-700, 2011. Disponível em:

https://www.researchgate.net/publication/220040302_Scepticism_and_Uncertainty_about_Cli mate_Change_Dimensions_Determinants_and_Change_over_Time. Acesso em: 14 fev. 2019.

WHITMARSH, L.; CORNER, A. Tools for a new climate conversation: a mixed-methods study of language for public engagement across the political spectrum. Global Environmental Change, [S.1.], v. 42, p. 122-135, 2017. Disponível em:

http://orca.cf.ac.uk/97309/1/Centre\%20right\%20narratives\%20FINAL.pdf. Acesso em: 14 fev. 2019. 